\title{
Translational Aesthetics
}

\section{ADAM DAYEM}

Rensselaer Polytechnic Institute

These drawings are part of ongoing design research exploring how computational drawing techniques can be used to create aestheticized spatial propositions. Operating in the abstracted two-dimensional realm of architectural representation, they are intended to create architectural ideas composed of form, light, and color. This research has been carried out in various design studios and visual studies classes over the past two years. The series drawings shown here is from one specific course - a first-year undergraduate visual studies course taught at Pratt Institute. The framework of a first year course presents particular opportunities and limitations in relation to the research agenda.

To create the drawings, students started with a simple assembly of five identical cubes. They were asked to build a three-dimensional digital model of the cubes, produce a landscape in which to locate the assembly, and then to explore the following issues in a series of iteratively developed drawings: subdivision of the given base geometry, ambiguity between figure of the assembly and the field in which it was located, ambiguity between two and three-dimensional readings of the drawing, superimposition and blending of line and tone, and projections of colored light. Drawings that dealt with these topics effectively became aesthetic endeavors. And this was the primary aim of the course, to start with fundamental digital drawing techniques that must be mastered in the framework of a first-year course, then show students how to move into a more speculative arena and a broader disciplinary discussion around the aesthetics of form, color, and light.

These drawings are part a design research agenda that extends beyond one particular class. In this research, drawing maintains its position as the primary mediator between idea and built form. It has become ever more possible, and is often extremely valuable, to close the gap drawings have traditionally bridged between idea and built form by engaging in the wide range of computational design and fabrication techniques currently available. However, this research takes a different tack. It posits that there is continued value in translational drawings, particularly when it comes to the aesthetics of architecture. Therefore, these drawings are meant to ask questions about what architecture could potentially be, both formally and aesthetically, rather than to provide any definitive answers. 


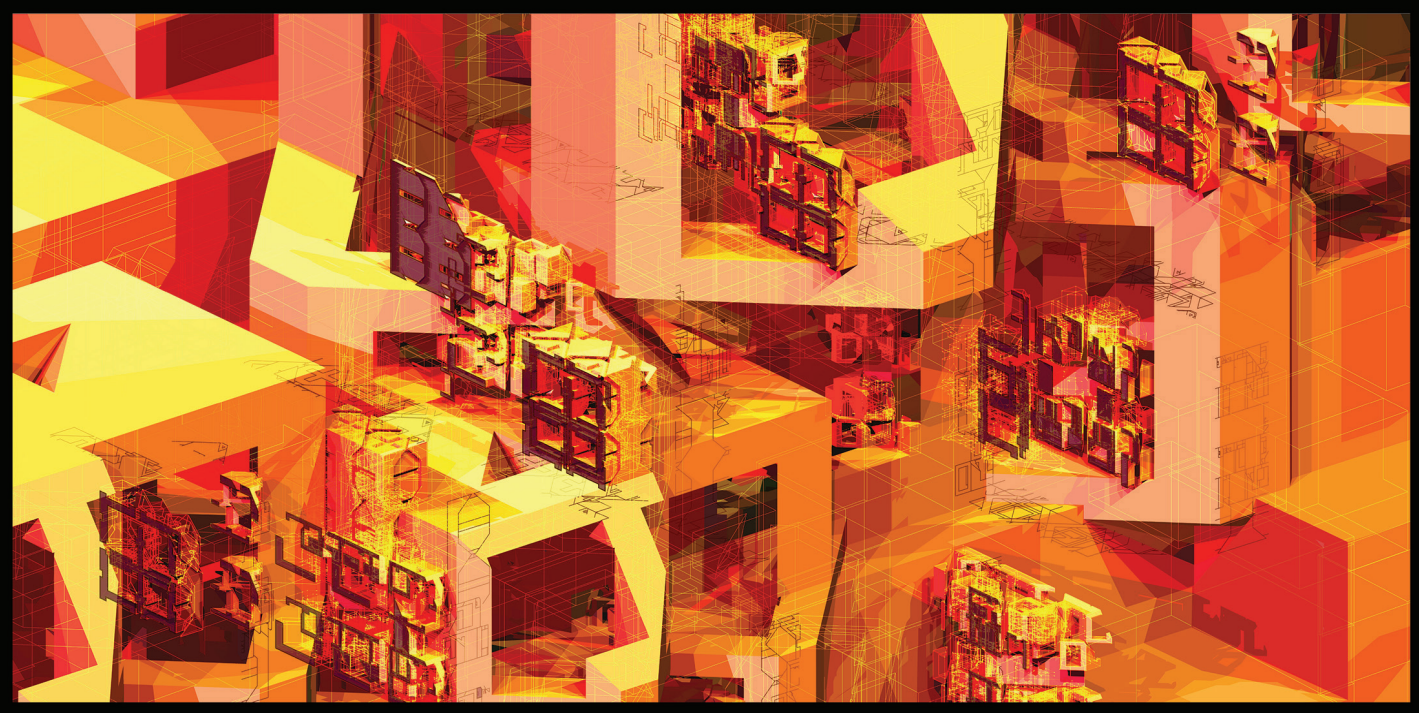

\section{Translational Aesthetics}
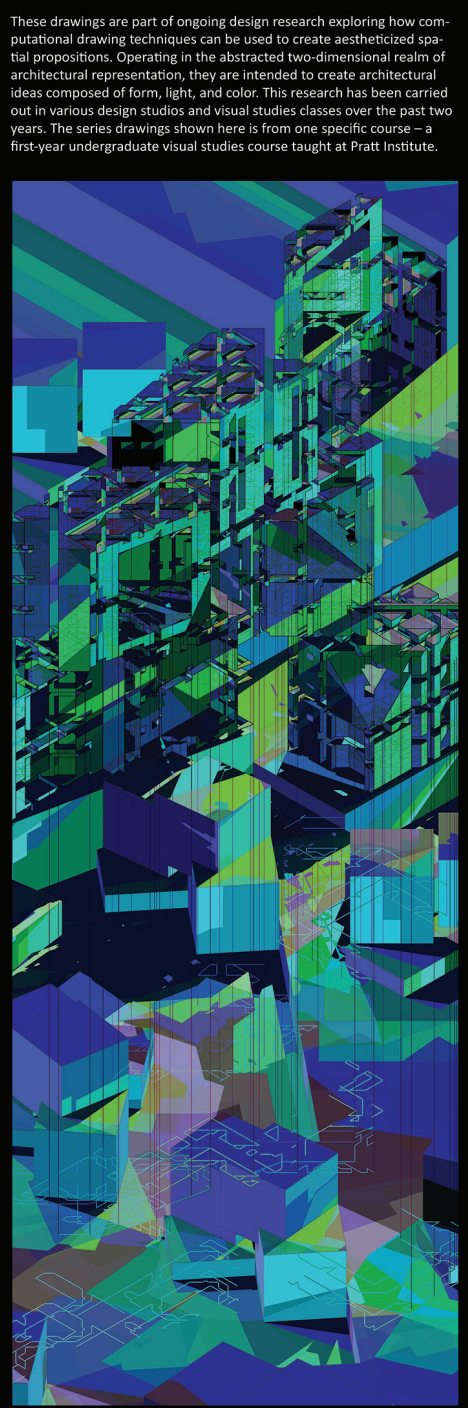
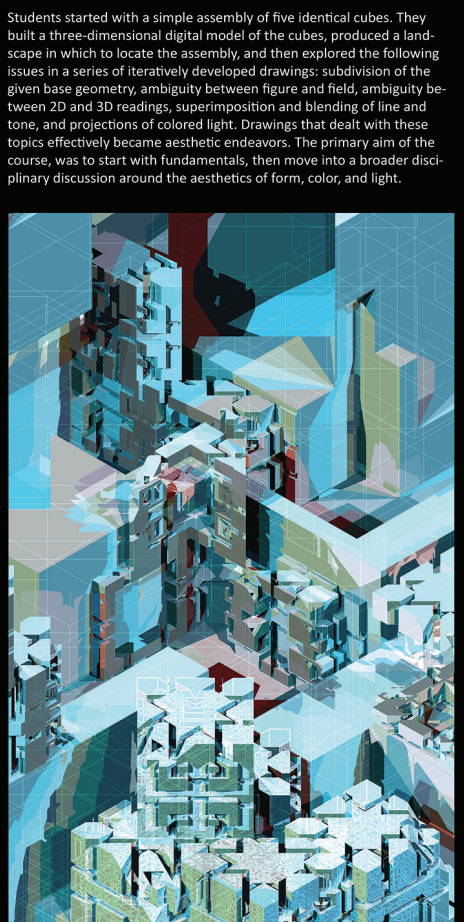
1.1.

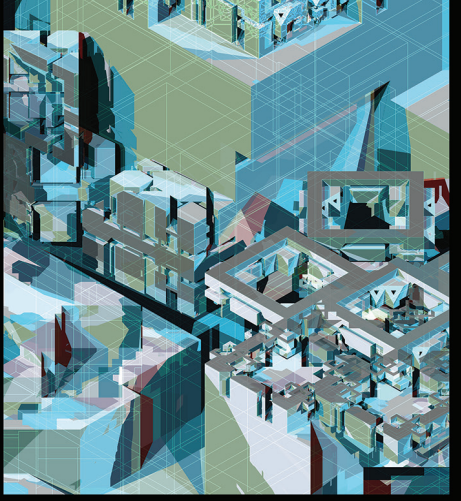

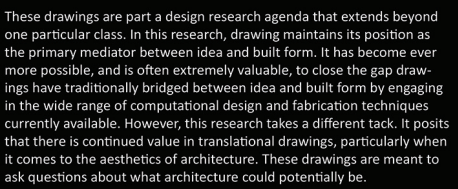
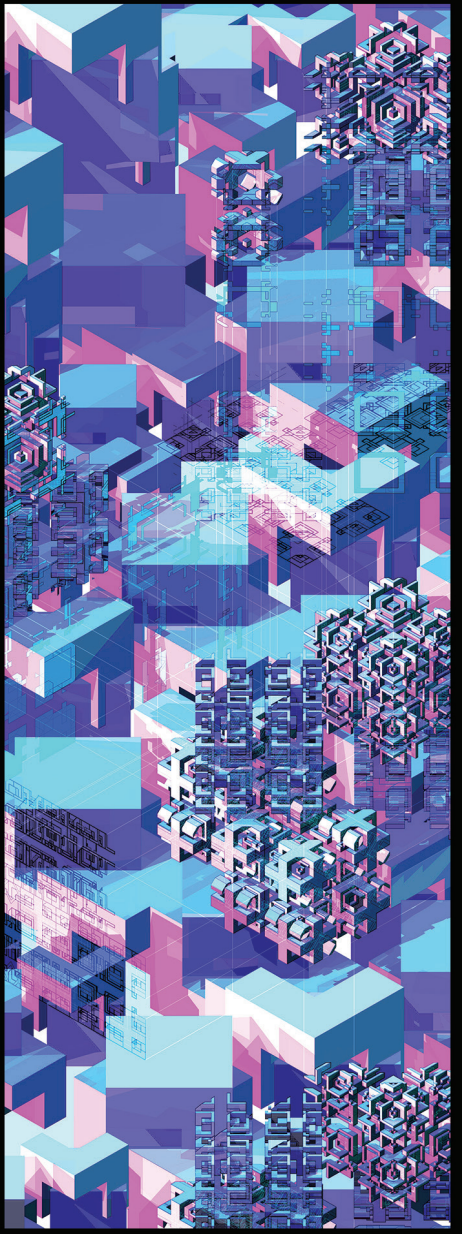